\title{
Accuracy of Ultrasounds in the Diagnosis of Placenta Previa by Nonradiologists in Cameroon
}

\author{
${ }^{1}$ Fouelifack Y Florent, ${ }^{2}$ Patrick BA Ohanda, ${ }^{3}$ Jeanne H Fouedjio, ${ }^{4}$ Jovanny T Fouogue \\ ${ }^{5}$ Loic D Fouelifa, ${ }^{6}$ Robinson E Mbu
}

\begin{abstract}
Objectives: Ultrasound evaluation could ensure early diagnoses prior to the onset of clinical manifestations. The use of ultrasound as a diagnostic tool for varying disease states is gaining ground in Africa; however, its operator dependence constitutes a major setback. Our main goal was to evaluate the accuracy of ultrasound in the diagnosis of placenta previa $(\mathrm{PP})$ in Cameroon, and especially its use by nonradiologists.
\end{abstract}

Materials and methods: We carried out a cross-sectional prospective study in the maternity unit of the Yaoundé Central Hospital during a period of 13 months (December 1, 2014 to December 31, 2015). Our study population involved women with prior cesarean section irrespective of the indication at least 28 weeks of gestational age. During surgery the diagnosis was confirmed. We included all women with a past history of cesarean section who underwent a 3rd trimester ultrasound scan (USS), especially in the last 4 weeks preceding the cesarean section.

Results: The mean age of our study population was 28.02 years ( \pm 6.13 years), with age extremes at 13 and 44 years respectively. Out of 761 women who underwent cesarean section, 153 had been diagnosed preoperatively with PP. All the USSs were transabdominal. Third trimester scans irrespective of the operator had a sensitivity of 82 , and $99 \%$ specificity. Among the

\footnotetext{
${ }^{1}$ Assistant lecturer, ${ }^{2,5}$ Medical Student, ${ }^{3}$ Lecturer, ${ }^{4}$ Resident ${ }^{6}$ Professor

${ }^{1}$ Department of Obstetrics and Gynecology of Higher Institute of Medical Technology of Nkolondom; Obstetrician and gynaecologist at the Obstetrics and Gynaecology Unit of the Yaoundé Central Hospital; National Coordinator of Research Education and Health Development Group "GARES - falaise" Dschang, Yaoundé, Cameroon

${ }^{2}$ Higher Institute of Medical Technology of Nkolondom, Yaoundé Cameroon

${ }^{3}$ Department of Obstetrics and Gynaecology, Faculty of Medicine and Biomedical Sciences of University of Yaoundé; Obstetrician and Gynaecologist at the Obstetrics and Gynaecology Unit of Yaoundé Central Hospital, Yaoundé I, Cameroon

${ }^{4}$ Department of Obstetrics and Gynecology- Faculty of Medicine and Biomedical Sciences of University of Yaoundé I, Cameroon

${ }^{5}$ Faculty of Health Sciences of University of Lomé, Togo; School of Armies Health Services of Lomé, Togo

${ }^{6}$ Department of Obstetrics and Gynaecology, Faculty of Medicine and Biomedical Sciences of University of Yaoundé I; Chief of the Obstetrics and Gynaecology Unit of Yaoundé Central Hospital Yaoundé, Cameroon

Corresponding Author: Florent Y Fouelifack P.O. Box: 31186 Yaoundé - Cameroon, Tel: +237 696312354, +237 675365346 e-mail: yfouelifack@gmail.com
}

operators, radiologists and obstetricians had the best sensitivity rates ( 83 and $81 \%$ respectively) as against $71.4 \%$ among other operators.

Conclusion: Ultrasound scanning is important in the antenatal period as a diagnostic tool for PP when carried out by radiologists and obstetricians. Routine use of the transvaginal and transperineal routes should be encouraged so as to gain in accuracy during 3rd trimester scanning. However, the nonradiologists need to be trained because of the accuracy lapses involving the USSs which they carry out.

Keywords: Accuracy, Cameroon, Diagnosis, Nonradiologists, Placenta previa, Ultrasound.

How to cite this article: Florent FY, Ohanda PBA, Fouedjio JH, Fouogue JT, Fouelifa LD, Mbu RE. Accuracy of Ultrasounds in the Diagnosis of Placenta Previa by Nonradiologists in Cameroon. Donald School J Ultrasound Obstet Gynecol 2016;10(4):403-408.

Source of support: Nil

Conflict of interest: None

\section{INTRODUCTION}

Placenta previa (PP) refers to the total or partial insertion of the placenta at the level of the lower uterine segment. ${ }^{1,2}$ It is the main cause of 3rd trimester pregnancy-related bleeding. ${ }^{3-5}$ The highest frequencies for this condition are in Africa, where the diagnosis is essentially a clinical one, with values in sub-Saharan Africa ranging from 0.3 to $11 \%{ }^{6}$ The value stands at $1.1 \%$ in the university teaching hospitals in Yaoundé in 2011. ${ }^{7}$ This is much lower in developed countries where PP is responsible for $0.03 \%$ of case of maternal mortality. ${ }^{8}$ Once suspected, ultrasound scan (USS) could confirm the diagnosis. Asymptomatic forms of PP represent 2 to $34 \%$ of cases. ${ }^{9,10}$ Early search for placental location prior to onset of symptoms is strategic for both pregnant women and care providers. ${ }^{11-13}$ Hence searching for placental insertion during 3 rd trimester scanning should be routine. In the USA, the use of ultrasound between 1940 and 1985 in the diagnosis of PP permitted a drop in the maternal mortality rate from 50.3/100,000 live births to less than 5/100,000, and a reduction in perinatal mortality from more than $91.8 / 1,000$ births to $5.2-10 / 1,000 .^{11}$

In Cameroon, the sprouting of ultrasound machines has resulted in the increased use of this technic. Notwithstanding, performing an USS requires knowledge and skills to ensure quality results. Understanding that in this 
context, the end results of an USS are operator-dependent; we opted not only to carry out this study so as to evaluate the quality of care made available to our patients, but also guide health care providers as to the quality of USS results made available to them. Our main objective was to evaluate the accuracy of USS in the diagnosis of PP especially that carried out by nonradiology operators. Specifically, we sought to determine the sensitivity, specificity, the positive and negative predictive values of USS results with respect to differing operators. Our confirmatory diagnosis was posed peroperatively during cesarean section.

\section{MATERIALS AND METHODS}

It was a prospective, cross-sectional study carried out at the Obstetrics and Gynecology Unit of the Yaoundé Central Hospital from the December 1, 2014 to the December 31, 2015 (13 months).

\section{Selection Criteria}

Our study population comprised all women who had undergone a cesarean section irrespective of indication. We included all women who had an obstetric USS no longer than 4 weeks prior to cesarean section. We excluded all women with uterine ruptures, women with obstetric USS older than 4 weeks prior to cesarean section, and women who did not consent to the study.

\section{Procedure}

The sampling was consecutive. The sample size was calculated using Lorentz formula: $\mathrm{N}=\left[\mathrm{z}^{2} \times \mathrm{p}(1-\mathrm{p})\right] / \mathrm{d}^{2}$, where $\mathrm{N}=$ sample size, $\mathrm{z}=$ adjusted confidence level (for a confidence level of $95 \%, z=1.96$ ), $\mathrm{p}=$ largest prevalence of PP published in African series at $11 \%,{ }^{6} \mathrm{~d}=$ accepted error margin (at about $5 \%$ ), where $n=151$ parturients. In a bid to grant strength to our findings, we recruited the maximum number of patients satisfying our inclusion criteria during the period of the study which was 761 .

Ultrasound scans were considered normal for all conclusions not mentioning PP (USS-), and pathological (USS+) for all conclusions mentioning PP.

BESSIS criteria is the most used in our context for the USS diagnosis of $\mathrm{PP}^{14}$ which considers as low-lying or previa placentas all inserted totally or partially at the zone extending from the dome of the bladder to a distance $40 \mathrm{~mm}$ behind the cervix on the posterior wall of the uterus, at the center of which is the internal cervical os.

Once recruited, all information obtained was transcribed into a preconceived tested data entry form. The obtained information included identification (age, marital status, profession, ethnicity, gravidity, parity, gestational age at the time of cesarean section); past history (PP, abortions, cesarean section); gestational age at the time of ultrasound in weeks; ultrasound diagnosis (PP, type of PP, normally inserted placenta); the qualification of the operator carrying out the USS (radiologist, obstetrician, general practitioner, radiological technicians, nurse, etc.); type of placental insertion discovered peroperatively; and the gestational age at the time of cesarean sectioning in weeks. We afterwards compared the type of insertion diagnosed by USS to our operative findings.

\section{Data Analysis}

Our data were transcribed into the Microsoft ${ }^{\circledR}$ Excel $^{\circledR} 2010$ software, and processed using the Epi-info version 7, IBM ${ }^{\circledR}$ Statistical Package for the Social Sciences (SPSS) Statistics version 21 and Stata version 11.SE. Indicators used for comparisons included sensitivity, specificity, and the rate of undiagnosed PP. Comparisons were first by operator qualification, then global irrespective of operator.

\section{Ethical Considerations}

Ethical clearance was obtained from the Ethical Committee of the University of Douala/Faculty of Medicine and Pharmaceutical Sciences. We also obtained permission from the Director of the Yaoundé Central Hospital to undertake this study. All information obtained was treated as very confidential in strict respect of medical norms.

\section{RESULTS}

Out of 826 parturients having undergone a cesarean section during the study period, 65 were excluded ( 60 for no availability of USS results whether done or not, and 5 due to uterine rupture), and 761 cases were therefore retained for analyses.

\section{Sociodemographic Profile}

The demographic and socioobstetrical profile of our study sample is shown in Table 1. Of 761 patients recruited for our study, the mean age was 28.02 ( \pm 6.13 years) 13 and 44 years, 320 parturients $(42.2 \%)$ were married. The mean gravidity was 3.16 pregnancies $( \pm 2.11)$ with extremes at 1 and 12 . The mean parity $2.41( \pm 1.63)$ with extremes at 0 and 11. The mean gestational age at the time of performing the 3 rd trimester USS $34.49 \pm 3.02$ weeks with extremes at 28 and 44 th week. At the time of cesarean section, it was 38.62 weeks $\pm 2.72(270.40 \pm 19.06)$ with extremes at 28.14 and 46.43 weeks. With regards to the neonates, 456 (59.9\%) were males and $305(40.1 \%)$ females. The mean weight stood at $3214.70 \mathrm{gm}( \pm 654.84)$ with extremes at 1200 and $5600 \mathrm{gm}$.

\section{Relationship between the Placental Location by USS and the Peroperative Location by Operator Group}

Table 2 shows the relationship between placental location found on ultrasound and location during surgery, according to the qualification of the various operators. 
Accuracy of Ultrasounds in the Diagnosis of Placenta Previa by Nonradiologists in Cameroon

Table 1: Sociodemographic and obstetrical profile of our study population

\begin{tabular}{llllll}
\hline Variable & $n$ & Minimum & Maximum & Mean & Standard deviation \\
\hline Age of patients & 761 & 13.00 & 44.00 & 28.02 & 6.12 \\
Gravidity & 761 & 1.00 & 12.00 & 3.16 & 2.10 \\
Parity & 761 & 0.00 & 11.00 & 2.41 & 1.63 \\
GA at 3rd USS (weeks) & 761 & 28.00 & 44.00 & 34.49 & 3.02 \\
GA at C-section (weeks) & 761 & 28.14 & 46.43 & 38.62 & 2.72 \\
Apgar of newborn at 5 minutes & 761 & 0.00 & 10.00 & 8.82 & 2.28 \\
Newborn weight & 761 & 1,200 & 5,600 & $3,214.70$ & 654.84 \\
Number of PNC & 761 & 0.00 & 12.00 & 4.83 & 1.77 \\
\hline
\end{tabular}

GA: Gestational age; USS: Ultrasound scan; PNC: Prenatal consultations

Table 2: Relationship between the placental location by USS and the peroperative location by operator group

\begin{tabular}{lllll}
\hline Peroperative location & & $P P$ & NIP & Total \\
\hline Radiologists & USS+ & 86 & 3 & 89 \\
& USS- & 17 & 487 & 504 \\
Obstetricians & Total & 103 & 490 & 593 \\
& USS+ & 29 & 1 & 30 \\
& USS- & 7 & 79 & 86 \\
Unprecised specialty & Total & 36 & 80 & 116 \\
& USS+ & 1 & 0 & 1 \\
& USS- & 1 & 22 & 23 \\
Radiology technicians & Total & 2 & 22 & 24 \\
& USS+ & 5 & 0 & 5 \\
& USS- & 2 & 14 & 16 \\
Nurses & Total & 7 & 14 & 21 \\
& USS+ & 3 & 0 & 3 \\
& USS- & 0 & 2 & 2 \\
General practitioners & Total & 3 & 2 & 5 \\
& USS+ & 1 & 0 & 1 \\
& USS- & 1 & 0 & 1 \\
& Total & 2 & 0 & 2 \\
USS (all operators) & USS+ & 125 & 4 & 129 \\
& USS- & 28 & 604 & 632 \\
& Total & 153 & 608 & 761 \\
\hline
\end{tabular}

USS+: PP on USS; USS-: No PP on USS; NIP: Normally inserted placenta

Of 761 cesarean section, PP constituted an operative finding in 153 , giving a frequency of $20.10 \%$ for PP in cesarean section at the Yaoundé Central Hospital.

As regards the operators, of 761 USS done, 593 (77.9\%) were by radiologists, $116(15.2 \%)$ by obstetricians, $24(3.2 \%)$ by operators of unspecified specialty and, 21 (that's $2.8 \%$ ) by radiology technicians.

\section{Indicators and Comparisons of Results}

Various indicators used for comparison between ultrasound diagnosis (for each operator) and intraoperative diagnosis are shown in Table 3.

In all (all operators considered), the sensitivity and specificity of ultrasound in the diagnosis of PP stood at 82 and $99 \%$ respectively, $18.30 \%$ cases of PP were undiagnosed on USS. By operator qualification, the most reliable scans were those performed by radiologists with sensitivity and specificity levels of 83 and $99 \%$. The number of cases undiagnosed by radiologists stood at $16.50 \%$. Among
Table 3: Indicators and comparisons of results

\begin{tabular}{lllll}
\hline $\begin{array}{l}\text { Qualification } \\
\text { of operators }\end{array}$ & $\begin{array}{l}\text { Total of } \\
\text { USS } \\
\text { performed }\end{array}$ & $\begin{array}{l}\text { Sensitivity } \\
(\%)\end{array}$ & $\begin{array}{l}\text { Specificity } \\
(\%)\end{array}$ & $\begin{array}{l}\text { Undiagnosed } \\
\text { PP (\%) }\end{array}$ \\
\hline Radiologists & 593 & 83 & 99 & 16.50 \\
$\begin{array}{l}\text { Obstetricians } \\
\text { Unspecified }\end{array}$ & 116 & 81 & 99 & 19.44 \\
$\begin{array}{l}\text { specialty } \\
\text { Radiology }\end{array}$ & 21 & 50 & 100 & 50.00 \\
technicians & & 71 & 100 & 28.57 \\
$\begin{array}{l}\text { Nurses } \\
\text { General }\end{array}$ & 5 & 100 & 100 & 0.00 \\
practitioners & 2 & 50 & $/$ & 50 \\
All operators & 761 & 82 & 99 & 18.30 \\
\hline & & & &
\end{tabular}

other specialties, obstetricians had the most reliable USS results with sensitivity and specificity values at 81 and 99\% respectively, and $19.44 \%$ of undiagnosed cases.

\section{DISCUSSION}

\section{Limiting Factors}

The main difficulty encountered was not having the same operator carry out all the USS, or have the same surgeon for all the surgeries, hence the possibility of interoperator or intersurgeon variability. Also due to context-related conditions, all USS were transabdominal although endovaginal and transperineal routes are credited with greater sensitivity and specificity. ${ }^{15-19}$

By the process of placental migration, the localization of the placenta may vary up to the end of the 3rd trimester. $^{20-23}$ Hence, a placenta described as low-lying in the 2nd trimester may be normally inserted in the majority of cases at term (54 à 94\%), especially if anteriorly located. To minimize the risk of error linked to this, we decided to use only USS not dating longer than 4 weeks prior to cesarean section.

\section{Sociodemographic Profile}

Of 761 parturients recruited, the mean age was 28.02 ( \pm 6.13 years) (Table 1$)$. The mean gravidity was 3.16 pregnancies $( \pm 2.11)$, the mean parity $2.41( \pm 1.63)$. The mean gestational age at the time of 3rd trimester scanning was $34.4901 \pm 3.02$ weeks, and at the time of cesarean 
sectioning was 38.62 weeks \pm 2.72 . The mean weight of the babies was $3214.70( \pm 654.84) \mathrm{gm}$. Other series had similar findings. ${ }^{24-26}$

\section{USS Diagnosis vs Operative Diagnosis}

Of 761 cesarean section carried out, $\mathrm{PP}$ was found peroperatively in 153 giving a frequency of $20.10 \%$ during cesarean section at the Yaoundé Central Hospital (Table 2). We could not find such a high prevalence in literature, but this could be explained by the fact that the Yaoundé Central Hospital is a reference center and also because this prevalence is a peroperative value as against a hospital value.

Of the 761 USS, 593 (77.9\%) were done by radiologists (Table 2). Nonradiologists performed 166 (15.2\%) by obstetricians, 21 (2.8\%) by radiology technicians, 24 (3.2\%) by personnel of unspecified qualification, 5 by nurses, and 2 by general practitioners.

\section{Comparison Indicators and Results}

By using our comparison indicators, we had a sensitivity of $82 \%$, a specificity of $99 \%$, and an $18.30 \%$ undiagnosed rate for PP (Table 3). All our patients underwent transabdominal scans during prenatal consultations. According to Boog, transabdominal scans frequently are associated with false positive results. ${ }^{27}$ According to Society of Obstetricians and Gynaecologists of Canada ${ }^{28}$ and Royal College of Obstetricians and Gynaecologists, ${ }^{15}$ endovaginal scans have better results (sensitivity: $87.5 \%$, specificity: $98.8 \%$ ); hence in the absence of magnetic resonance imaging, endovaginal USSs constitute the gold standard for the diagnosis of PP. ${ }^{16}$ Endovaginal and transperineal routes of USS should be encouraged in our context so as to improve on the accuracy of USS as a diagnostic tool for PP in the 3rd trimester of pregnancy.

Sensitivity rates among the radiologists were 0.83 with a specificity of 0.99 (Table 3). Among nonradiologists, obstetricians had sensitivity and specificity rates of 81 and $99 \%$ respectively. In the other groups (general practitioners, nurses, radiological technicians, etc.), the accuracy of the scans was much reduced with undiagnosed cases spanning 28.57 to $50 \%$ (Table 3). Hence, among nonradiologists, obstetricians were outstanding as regards the USS diagnosis of PP. This is logical considering that outside radiology and obstetrics, the other medical training courses do not lay emphasis on the mastery of ultrasound technics. Also, the small numbers of ultrasounds performed by other specialties could influence on our results.

In some countries, other specialists outside radiologists and paramedical workers were trained in USS and other disciplines like interventional radiology, ${ }^{29}$ trauma medicine, ${ }^{30-32}$ anesthesia, ${ }^{33-35}$ emergency medicine, ${ }^{36-42}$ cardiology ${ }^{43,44}$ rheumatology, ${ }^{45-47}$ gastroenterology, ${ }^{48}$ parasitology, ${ }^{49}$ and neurology. ${ }^{50}$ The accuracy of the scans performed by these trained workers was similar to scans performed by radiologists.

The first experience of this in Africa was carried out in Rwanda in 2008. ${ }^{51}$ Here, an American nongovernmental organization called "Partners in Health" in a bid to improve on patient care, equipped two rural district hospitals with ultrasound equipment, and trained their staff (mainly nonradiologists) in the use of these equipment. Eleven weeks after their departure, an independent organization was called around to evaluate the quality of their results. They found out that USS had permitted an improved management and hence the prognosis of $43 \%$ of patients, and that the rates of concordance of USS results stood at a stunning $96 \%$ when compared to the evaluators who were radiologists. Obstetrics got the chunk of the improvement (determination of gestational age, fetal presentation, placental location), but also abdominal, cardiac, renal, pleural, and vascular diseases as well as echo-guided procedures. Expanding such an initiative in developing countries would certainly contribute toward improving on the accuracy of USS, and therefore, the overall health of its population.

\section{CONCLUSION}

Ultrasound scanning remains a very important diagnostic tool in the prenatal consultation setting in Cameroon, especially when carried out by radiologists and obstetricians. It would be wise to encourage the use of transperineal as well as the endovaginal routes because of their increased accuracy in the 3rd trimester diagnosis of PP. However, other nonradiologist health care providers need to be trained because in this group the quality and accuracy of the USS results remains wanting.

\section{ACKNOWLEDGMENTS}

The authors heartily appreciate the administration of the Yaoundé Central Hospital for having eased in carrying out of this study as well as the team working at the Obstetrics and Gynecology Unit for their support during data collection. Sincere thanks equally go to all our patients, radiologists, and all the surgeons who enabled us to obtain all necessary information toward the publishing of this study. Aside the individual contribution of each of the authors, this study received no financial assistance.

\section{CONTRIBUTIONS OF AUTHORS}

Florent $Y$ fouelifack and Patrick BA Ohanda conceived the study, and participated in data collection, write-up, and editing of the manuscript. Florent $Y$ Fouelifack, Jeanne H Fouedjio, Loic D Fouelifa, and Jovanny T Fouogue 
participated in the conception, data collection and analysis, as well as write-up and editing of the manuscript. Robinson E Mbu supervised the study from its conception up to write-up of the manuscript. All the authors read and approved the final manuscript.

\section{REFERENCES}

1. Miliez J. Hémorragie du troisième trimestre de la grossesse: orientation diagnostic. Rev Prat 1991 Mar 21;41(9):835-838.

2. Cabrol D, Pons JC, Goffinet F. Traité d'obstétrique, Placenta prævia. Flammarion Médecine 2003; p. 922-926.

3. Frederiksen MC, Glassenberg R, Stika CS. Placenta previa: a 22-year analysis. Am J Obstet Gynecol 1999 Jun;180(6 Pt 1): 1432-1437.

4. Ezechi OC. Mortalité maternelle: hémorragie du troisième trimestre de la grossesse. Int J Obstet Gynecol 2004;24:372-373.

5. Silver RM. Abnormal placentation: placenta previa, vasa previa, and placenta accreta. Obstet Gynecol 2015 Sep;126(3): 654-668.

6. Cresswell JA, Ronsmans C, Calvert C, Fillipi V. Prevalence of placenta previa by world region: a systematic review and meta analysis. Trop Med Int Health 2013 Jun;18(6):712-724.

7. Pierre MT, Gisèle KF, Robinson EM, Inoussa N, Luc K, Joseph NF. Placenta previa at University Hospital Yaoundé, Cameroon. Int J Gynecol Obstet 2013 Mar;120(3):286-288.

8. Sinha P, Kuruba N. Ante-partum haemorrhage: an update. Int J Obstet Gynecol 2008 May;28(4):377-381.

9. Cotton DB, Read JA, Paul RH, Quilligan EJ. The conservative aggressive management of placenta previa. Am J Obstet Gynecol 1980 Jul 15;137(6):687-695.

10. Foscolos P. Données statistiques sur le placenta previa. J Internat Coll Surgeous 1964;42(1):40-46.

11. McShane PM, Heyl PS, Epstein MF. Maternal and perinatal morbidity resulting from placenta previa. Obstet Gynecol 1985 Feb;65(2):176-182.

12. Mindel S. Role of imager in developing world. Lancet 1997 Aug 9;350(9075):426-429.

13. Allahdin S, Voigt $S$, Htwe TT. Management of placenta previa and accreta. J Obstet Gynaecol 2011;31(1):1-6.

14. Bessis R, Brignon C, Shneiderl. Localisation placentaire échographique dans les insertions basses; difficultés: le placenta migrateur Soirée échographique. Gynecol Obstet 1976;(5):3751.

15. Royal College of Obstetricians and Gynaecologists (RCOG). Placenta previa and placenta previa accreta: diagnosis and management. Vol. 12. London (UK): RCOG; 2005. p. 27.

16. Leerentveld RA, Gilberts EC, Arnold MJ, Wladimirof JW. Accuracy and safety of transvaginal sonographic placental localization. Int J Obstet Gynecol 1990 Nov;76(5 Pt 1):759-762.

17. Adeyomoye AA, Ola ER, Arogundade RA, Awosanya GO, Abudu OO. Comparison of the accuracy of trans-abdominal sonography (TAS) and transperineal sonography (TPS) in the diagnosis of placenta previa. Niger Postgrad Med J 2006 Mar;13(1):21-25.

18. Yang JI, Lim YK, Kim HS, Chang KH, Lee JP, Ryu HS. Sonographic findings of placental lacunae and the prediction of adherent placenta in women with placenta previa totalis and prior cesarean section. Ultrasound Obstet Gynecol 2006 Aug;28(2):178-182.

19. Gouhar GK, Sadek SM, Siam S, Ahmad RA. Role of transperineal sonography in diagnosis of placenta previa/ accreta: a prospective study. Egypt J Radiol Nucl Med 2012 Dec;(43):637-645.

20. Heller HT, Mullen KM, Gordon RW, Reiss RE, Benson CB. Outcomes of pregnancies with a low-lying placenta diagnosed on second-trimester sonography. J Ultrasound Med 2014 Apr;33(4):691-696.

21. Becker RH, Vonk R, Mende BC, Ragosch V, Entezami M. The relevance of placental location at 20-23 gestational weeks for prediction of placenta previa at delivery: evaluation of 8650 cases. Ultrasound Obstet Gynecol 2001 Jun;17(6):496-501.

22. Oppenheimer L, Holmes P, Simpson N, Dabrowski A. Diagnosis of low-lying placenta: can migration in the third trimester predict outcome? Ultrasound Obstet Gynecol 2001 Aug;18(2):100-102.

23. Lodhi SK, Khanum Z, Watoo TH. Placenta previa: the role of ultrasound in assessment during third trimester. J Pack Med Assoc 2004 Feb;54(2): 81-83.

24. Oyelese Y, Smulian JC. Placenta previa, placenta accreta, and vasa previa: review. Obstet Gynecol 2006 Apr;107(4): 927-941.

25. Taipale P, Hiilesmaa V, Ylöstalo P. Transvaginal ultrasonography at 18-23 weeks in predicting placenta previa at delivery. Ultrasound Obstet Gynecol 1998 Dec;12(6):422-425.

26. Faiz AS, Ananth CV. Etiology and risk factors for placenta previa: an overview and meta-analysis of observational studies. J Matern Fetal Neonatal Med 2003 Mar;13(3): 175-190.

27. McClure N, Dorman JC. Early identification of placenta previa. Br J Obstet Gynaecol 1990 Oct;97(10):959-961.

28. Society of Obstetricians and Gynaecologists of Canada. Diagnosis and management of placenta previa. Int J Gynecol Obstet Canada 2007 Mar;29(3):261-273.

29. Thomson KR. Interventional radiology. Lancet 1997 Aug 2;350(9074):354-358.

30. Hsu JM, Joseph AP, Tarlinton LI, Macken L, Blome S. The accuracy of focused assessment with sonography in trauma (FAST) in blunt trauma patients: experience of an Australian major trauma service. Injury 2007 Jan;38(1):71-75.

31. Foale CM, Kaleri AY, Sargsyan AE, Hamilton DR, Melton S, Martin D, Dulchavsky SA. Diagnostic instrumentation aboard ISS: just-in-time training for non-physician crewmembers. Aviat Space Environ Med 2005 Jun;76(6) 594-598.

32. Abu-Zidan FM, Abusharia MI, Kessler K. Surgeon-performed sonographic findings in a traumatic trans-anal rectal perforation. World J Emerg Surg 2011 Aug 12;6:26.

33. Adam B, Jim C, Otto C. Ultrasound in Emergency Care. 2004;104.

34. Hatfield A, Bodenham A. Portable ultrasound for difficult central venous access. Br J Anaesth 1999 Jun;82(6):822-826.

35. Bodenham AR. Editorial II: Ultrasound imaging by anaesthetists: training and accreditation issues. Br J Anaesth 2006 Apr;96(4):414-417.

36. Whitfield C, Garner JP. The early management of gunshot wounds part II: the abdomen, extremities and special situations. Trauma 2007;9(1):47-71.

37. Brooks A, Davies B, Smethhurst M, Connolly J. Prospective evaluation of non-radiologist performed emergency abdominal ultrasound for haemoperitoneum. Emerg Med J 2004 Sep;21(5):580-581.

38. Busch M. Portable ultrasound in pre-hospital emergencies: a feasibility study. Acta Anaesthesiol Scand 2006 Jun;50(6): 754-758. 
39. Nelson BP, Chason K. Use of ultrasound by emergency medical services: a review. Int J Emerg Med 2008 Dec;1(4): 253-259.

40. Wise J. Medical imaging: everyone's a radiologist now. Br Med J 2008 May 10;356(7652):1041-1043.

41. Dent B, Kendall RJ, Boyle AA, Atkinson PR. Emergency ultrasound of the abdominal aorta by UK emergency physicians: a prospective cohort study. Emerg Med J 2007 Aug;24(8):547-549.

42. Atkinson P, Boyle A, Robinson S, Campbell-Hewsson G. Should ultrasound guidance be used for central venous catheterisation in the emergency department? Emerg Med J 2005;22:158-164.

43. Levin DC, Rao VM, Maitino AJ, Parker L, Jonathan HS. Comparative increases in utilization rates of ultrasound examinations among radiologists, cardiologists, and other physicians from 1993 to 2001. J Am Coll Radiol 2004 Aug;1(8):549-552.

44. Concannon E, McHugh S, Healy DA, Kavanagh E, Burke P, Clarke Moloney M, Walsh SR. Diagnostic accuracy of nonradiologist performed ultrasound for abdominal aortic aneurysm: systematic review and meta-analysis. Int J Clin Pract 2014 Sep;68(9):1122-1129.

45. Speed CA, Bearcroft PW. Musculoskeletal sonography by rheumatologists: the challenges. Rheumatology 2002 Mar;41(3):241-242.
46. Atchia I, Birrell F, Kane D. A modular, flexible training strategy to achieve competence in diagnostic and interventional musculoskeletal ultrasound in patients with hip osteoarthritis. Rheumatology 2007 Oct;46(10):1583-1586.

47. Naredo E, D'Agostino MA, Conaghan PG, Backhaus M, Balint P, Bruyn GA. Current state of musculoskeletal ultrasound training and implementation in Europe: results of a survey of experts and scientific societies. Rheumatology 2010 Dec;49(12):2438-2443.

48. Jamieson CP, Denton ER, Burnham WR. Do gastroenterologists want to be trained in ultrasound? A national survey of trainees in gastroenterology. Gut 1999 Jan;44(1):123-126.

49. Carpio MD, Mercapide CH, Salvitti JC, Uchiumi L, Sutercic J, Panomarenko H. Early diagnosis, treatment and follow-up of cystic echinococcosis in remote rural areas in Patagonia: impact of ultrasound training of non-specialists. PLoS Negl Trop 2012 Jan;6(1):1444.

50. RiopelleJM, Busch EH, Wood DG, Viswanathan S, Mitchell MR, Celentano WJ. Ultrasound-guided internal jugular venous cannulation: an introduction for non-radiologists to a technique that is here to stay. J La State Med Soc. 2001 Mar;153(3): 142-152.

51. Shah SP, Epino H, Bukhman G, Umulisa I, Dushimiyimana JM, Reichman A, Noble VE. Impact of the introduction of ultrasound services in a limited resource setting: rural Rwanda 2008. BMC Int Health Hum Rights 2009 Mar 27;9:4. 